\title{
Complementarity of Reading from Paper and Screen in the Development of Critical Thinking Skills for 21st-century Literacy
}

\begin{abstract}
The skill of reading undergoes dramatic changes due to the change of reading interface readers are exposed to. Readers who want to be active participants of knowledge society need to perceive it as more than just a receptive skill.

The study aims to assess the condition of homo legens, diagnose what kind of reading interface preferences characterize 21st-century readers, how they respond to texts considering reading both digitally and in print, accepting or viewing critically the underlying ideology of the text.

The analysis of the collected data attempts to determine if the reported preferences are conducive to the development of critical thinking skills for 21st century literacy, which include understanding complex ideas, evaluating evidence, weighing alternative perspectives and constructing justifiable arguments.
\end{abstract}

Keywords: literacy, screen vs. paper reading, note-taking, critical thinking skills, digital literacy.

\section{Literacy under Construction}

The act of reading is a fairly recent learned behavior that uses the neural circuits initially developed for language, coordination, and sight. Taking into consideration recent finding of the remains of homo sapiens in Morocco dating back to 300,000 BC (Gibbons, 2017) and the Danube script from 5th millennium $\mathrm{BC}$ in Central Europe, it can be roughly estimated that literacy accompanies homo sapiens in only $2 \%$ of its evolution. As Wolf $(2010$, p. 3$)$ claims we were 
never born to read, but our neural circuits recycled to do so from cortical areas that were originally devoted to different functions like spoken language and encoding visual objects (Daheany, 2009, p. 121). For centuries literacy remained a skill limited to a small number of people $(12.05 \%$ in 1800$)$ who were associated with power, prestige, and intellectual elite. It has taken over 200 years to reverse the ratio of the illiterate $(14.70 \%)$ to literate population and to become more democratic. The last two centuries again constitute just $2 \%$ of homo legens evolution, which gains its momentum now. At present, it is the $85.3 \%$ of global population who may identify themselves as homo legens, this dramatic change is illustrated in Figure 1, which presents literacy for the period 1800-2014.

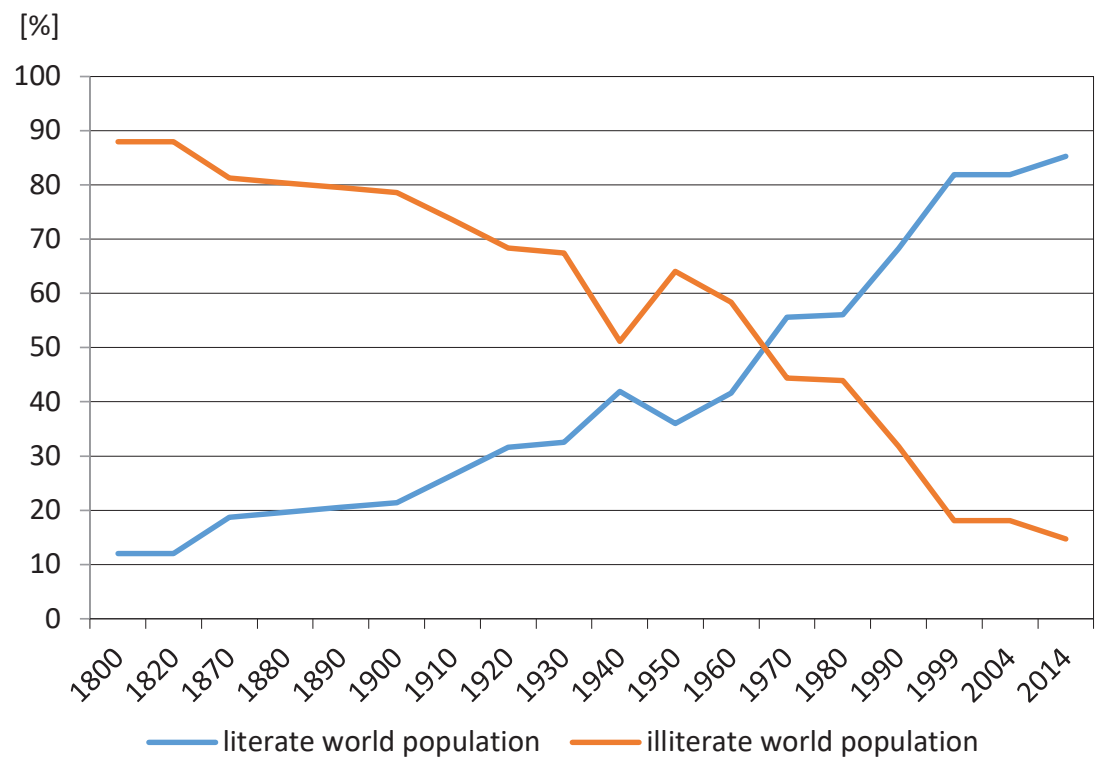

Figure 1. Literacy for the period 1800-2014 (data based on Roser \& OrtizOspina, 2018).

What is more, at present over $54 \%$ of global population are active Internet users (www.statista.com), which can be compared to the literacy level in 1990. It is interesting whether readers' interface preferences will keep pace with the development of technology and the Internet. More and more people have access to the electronic media; yet, irrespective of their reading purposes their reading comprehension both in L1 and L2 is often impaired. It may result from the fact that they have not developed sound skills to comprehend a paper written text. As Vidal-Abarcal, Mañá, \& Gil (2010) emphasise the sound reading skills developed form reading a paper text support the location of relevant information in digital texts. Location is impaired because of the distractions present in the hypertexts, which do not leave cognitive resources for viewing critically the 
underlying ideology of the text. That is why Salter (2018) emphasises the importance of developing different set of skills: digital literacy and navigation skills.

The development of digital literacy and navigation skills would contribute to the increase of critical thinking which is the ultimate goal of tertiary education. As far as the skills of a critically thinking reader are concerned, they are best summarised by Schumm and Post (1997) who divide them into: basing judgements on evidence, asking penetrating questions and evaluating ideas, distinguishing between opinions and facts, and reflecting on ideas. The important factor underlying all of the above-enumerated skills is time and concentration which in case of reading from the screen are decreased. However, the study by Wu and Chen (2011) shows that students have an intuitive understanding of how best to find, comprehend and retain the text, as majority of tertiary students will begin their research using screen-based text (benefiting from advanced search functions and the like), and then after having chosen the appropriate text will often print it to be able to better digest the text.

As Salter (2018) indicates, we are all on a journey of finding a balance between reading on paper and reading electronically. The fundamental assumption of the study is the increase in electronic reading preference and a wider range of application of electronic tools supporting the reader, which result in the development of most important skill at the tertiary education level-critical thinking. As critical thinking skills involve an ongoing questioning of takenfor-granted assumptions (Santos \& Fabricio, 2006), the aim of this work is to examine the existing interface preference of the readers and show how finding balance between interfaces influences development of critical thinking skills. We acknowledge that there are considerable discussions among the researchers as to what can be defined as a critical thinking skill, however, for the purpose of our study we employed only four major ones. The first skill involves comprehending complex ideas, undeniably only after having comprehended an idea one can proceed to asking penetrating questions. Then, the two skills of basing judgements on evidence and evaluating ideas indicated by Schumm and Post (1997) are combined into a single skill of evaluating evidence. Finally, distinguishing between opinions and facts and constructing justifiable arguments are examined to see which interface is the most conducive to their development.

\section{Reading from Paper versus Reading from Screen}

The major difference between paper versus screen reading is the fact that reading from paper is a linear experience involving concentration and emotional 
engagement (Durant \& Horava, 2015) and screen reading is a multi-layered experience (Walsh, 2016), as electronic documents allow readers to leave one resource and explore a range of alternative resources (Anderson-Inamn \& Horney, 2007). The other areas of difference involve: preferences, manipulation, eye-fatigue and movement, as well as comprehension.

\section{Reading Interface Preference}

As the concept of 'digital natives' has been debunked by Bennett, Maton, and Kervin (2008), it cannot be assumed that all students are comfortable with technology. The correct generalisation would involve the assumption that different students will display different media skills. Ramirez Leyva (2006) proved that nearly $80 \%$ of 687 surveyed students preferred to read text on paper as opposed to a screen in order to "understand it with clarity," and Nicholas and Lewis (2008) showed that when it comes to reading a book, even millennials (generation born between 1980-2000) prefer print.

\section{Text Navigation and Manipulation}

One of the reasons of a strong paper interface preference may result from the fact that reading has to be considered not only an intellectual but also a physical activity. The implicit feel of where you are in a physical book turns out to be more important than we realized (Sellen \& Harper, 2002), and the smooth feel of paper and the rich colors of illustrations are largely lost in e-book reproductions (Paul, 2013). Yet another aspect of physicality involved in reading is indicated by Jabr who emphasises the physical aspect of it claiming that

text is a tangible part of the physical world we inhabit; turning the pages of a paper book is like leaving one footprint after another on the trail—there's a rhythm to it and a visible record of how far one has traveled. All these features not only make text in a paper book easily navigable, they also make it easier to form a coherent mental map of the text. (2013, p. 100)

Additionally, Jabr (2013) claims that modern screens and e-readers fail to adequately recreate certain tactile experiences of reading on paper that many people miss and prevent people from navigating long texts in an intuitive and satisfying way. The study such as Mangen, Walgermo, and Brønnick (2013) suggests that the ability to identify your passage through a text in a tactile way is important to learning, and Wästlund et al. (2005) prove that scrolling requires 
a reader to consciously focus on both the text and how they are moving, and it drains more mental resources than turning a page, which is a simpler and more automatic gesture.

\section{Eye Movements and Fatigue}

Yet another reason of a strong paper interface preference could result from the fact that less attention is needed when reading from paper. Gudinavičius (2016) suggests that less attention is needed to read from paper in comparison to any size or type of screen. Fatigue, being the physical aspect of reading, also cannot be overlooked as far as reading is concerned. Jeong (2012) in the study regarding eye fatigue proves that students had significantly greater eye fatigue after reading e-books than after reading paper books. As regards eye movement, thanks to eye-tracking technologies, Zambarbieri and Carniglia (2012) show that reading from paper and screen do not differ significantly in terms of oculomotor behaviour. The discomfort that people feel when reading from a screen, rather than paper, is described by Gerlach and Buxmann (2011) as "haptic dissonance," which is explained as an unfamiliarity with the feel of e-books compared to print books.

\section{Comprehension}

Dillon (1992), reviewing literature on reading from paper versus screens concludes that comprehension of material is not negatively affected by interface it is presented on; however, having well developed single-text comprehension skills (acquired in reading for paper) improve navigation and make readers less distracted by misleading cues (Salmerón, Cerdán, \& Naumann, 2015). Kaufmann and Flanagan's (2016) study proves that using computer screens for learning worsened abstract thinking (e.g., recalling why some events occurred), but improved recall of concrete details (e.g., recall of dates of certain events). Several studies show that misleading cues such as task switching tend to impair learning and decrease comprehension of digital texts (Kirschner \& van Merriënboer, 2013). 


\section{Description of the Study}

The study focuses on basic concepts referring to paper versus digital reading aiming to determine general reading and studying interface preferences of the first year students of English Department. Furthermore, it is also interesting to check the need to print electronically available materials and the interfaces students found most conducive to remember new information. As far as paper/ screen preferences of a critically thinking readers are concerned, they will be analysed in the following categories: understanding complex ideas, evaluating evidence, weighing alternative perspectives, and constructing justifiable arguments.

Table 1

Age and gender of study participants

\begin{tabular}{lcccccccc}
\hline $\begin{array}{l}\text { Students'age } \\
\text { and gender }\end{array}$ & 19 & 20 & 21 & 22 & 23 & 24 & $\mathrm{~F}$ & $\mathrm{M}$ \\
\hline paper & 1 & 44 & 16 & 1 & 1 & 2 & 57 & 8 \\
\hline paper/screen & 1 & 4 & 1 & & & & 5 & 1 \\
\hline screen & & 4 & & & & & 2 & 2 \\
\hline
\end{tabular}

The subjects of the study are 75 first year students at the University of Silesia in Katowice, Poland (57 females and eight males). The age range of study participants is 19-24, falling into three groups of students preferring either paper, paper/screen, or just screen (Table 1). The data collection tool employed in the study includes a questionnaire with 41 questions. The subjects filled in the questionnaire on April 25 and May 9, 2018.

\section{Results and Analysis}

\section{Subjects' Preferred Reading Interface}

One of the crucial aims to find out in the study related to students general reading interface preferences. In Figure 2, which presents the subjects' answer concerning their preferred medium for reading, it is clear that the percentage is strikingly higher for paper, which confirms findings from previous studies by Ramirez Leyva (2006), and Nicholas and Lewis (2008). 


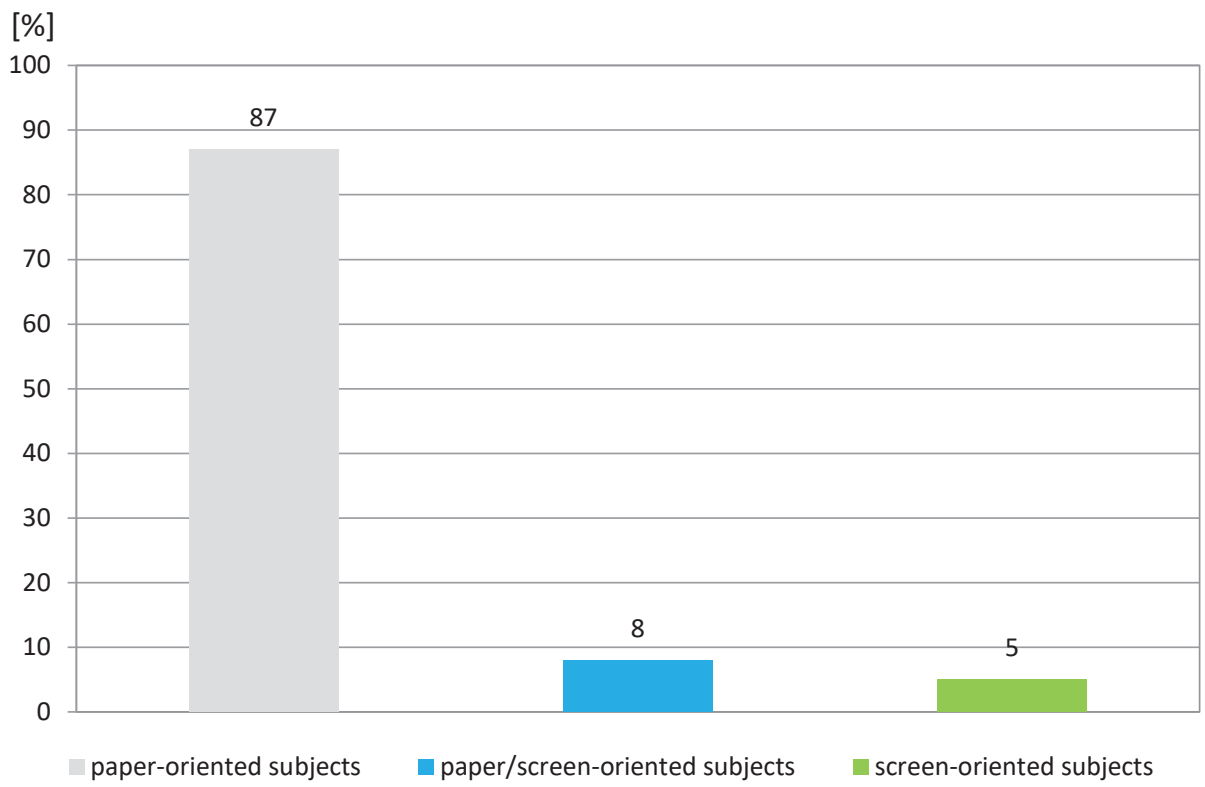

Figure 2. Subjects' preferred reading interface.

Subjects substantiate their answers with the following comments, which are presented according to the interface they preferred. ${ }^{1}$

Paper (55) - it's better for my eyes (17), I focus better (14), I like to touch real paper (13), more convenient (10), it's easier to make notes (6), I like the smell of pages (4), I don't get tired easily (4), I like traditional way of reading (3), more practical (2), it's easier to remember important things (2), it's easier to understand issues presented in books (2), it enables me to go through pages faster, I feel more engaged, it feels more real;

Paper/screen (6) - it doesn't make any difference to me;

Screen (4)-less tiring for eyes, option of changing fonts and I can take it anywhere, I can easily organise my materials and take them anywhere with me, it's more convenient.

A we can see, the paper-oriented readers seem to be more aware of the processes underlying reading, indicating not only to convenience, which was most highlighted by screen-oriented subjects. The paper-oriented students take into consideration the processes of remembering, comprehension as well as the sense not included in the studies so far, that is, the sense of smell. It is important to note that previous studies do not indicate that sense of smell is essential as far as reading is concerned.

\footnotetext{
${ }^{1}$ All the answers have been given in the original spelling.
} 


\section{Interface Preferred for Studying}

Another point of interest is interface chosen by students for studying. Here the results overlap with their general reading preferences, that is why only their substantiations for their choices are presented. They are presented according to their reading interface preference as well as the following features: facilitated focus and recall, fatigue, proximity, manipulation, and studying effects, which are all enumerated by paper-oriented subjects (55).

Facilitated focus and recall: I don't like learning from the electronic devise; When studying I prefer to print stuff, it helps me remembering things; when I study for a test I prefer to make source notes on computer then I print them; It's easier to remember it but sometimes I just look at my phone (when I don't want to waist my time); I prefer paper than screen; If I used electronic version I would get easily distracted; They're more reliable (usually); I feel like they are more trustworthy; I focus on the most important facts and the screen distracted me; Nothing else distracts my attention; I can focus better on them; It's better for me because I can easily focused on what I am reading; I can focus more, when I study from paper sources.

Fatigue: It's better because I don't make my eyes tired.

Proximity: I prefer to learn from my notes because I have all close to me.

Manipulation: I can mark important sentences and make notes; It's better cause I take notes and circle things I have problem with; Important information can be highlighted; We are given many handouts on paper; I can make notes and focus later on them; I like touching paper and making notes when necessary; I can make notes on them, highlight, underline them; I usually highlight the most important information and it is easier for me to learn it later; I like to highlight and write information on the side; I can make notes; Paper because I can make notes; I can make notes on it; Sources on paper are handy and I can highlight or underline most important pieces of information; Of course I refer to the sources on paper because it's more convenient for me and thanks that I could add my own notes to the notes on paper; I can underline some important things for example; I can write on a page of paper; I can use markers and find key words; I can easily highlight the most important informations. I can make notes underline things highlight them; I can make notes at the same time which helps me remember it better; I have my sources on paper not on screen; it's easier way to remember things; I can change them by writing everywhere; It is more comfortable having notes on paper and reading it in bed for example; I have everything organized so I have easy access to them; I can highlight sources and make notes next to the next. I prefer the sources on paper because I can take notes on it; I can easily highlight the most important info; Because I can mark a lot of different things, underline the most 
important thing; It's easier to make notes; On paper because I prefer notes which are made by myself; Because I do a lot of notes and I can take them everywhere; I can underline important facts, write my thoughts; I like to write on a handouts; I borrow some books for the library; It's easier to make notes on them + they are more reliable; On paper - I can highlight whatever I want and it is easier to focus; I can highlight the most important information; I like taking notes on paper I work on; If they are available; I'm able to take notes on paper and highlight information; Paper - I study by making notes.

Studying effects: I tend to learn faster and more efficiently when reading a paper version of the test; I learn the most by writing on paper \& reading it later; I think is easier to learn; I prefer sources on paper because it help me learn enough good; I learn easily from paper; I learn better and can focus better while looking at paper I can make notes on paper; Because it is more comfortable to learn from the paper notes; It is easier for me to learn from paper, I can't explain it.

As far as paper-/screen-oriented subjects' comments (6) are concerned, it was difficult to categorize them, which is why they are only randomly listed here: I use both paper and digital sources; It's a habit from the past; It depends in what form I have it; only if that's necessary; it's hard to get it currently it's easier to learn from the sources from the Internet on screen; I prefer using sources on screen.

Screen-oriented subjects' comments (4): when I study I prefer the fastest ways to find proper informations, sources; I write notes in the electronic version; I find informations on the internet; it's easier to find any informations on computer.

The most important factor which makes students choose paper refers to manipulation. The reason of their choices can be motivated by the strong inclination to avoid "haptic dissonance" and to feel familiarity with the print books and the ease of taking hand-written notes is the most salient factor in manipulation of the text. The results obtained from the screen-oriented students show that studying for them is mere information finding.

\section{The Frequency of Printing Electronic Materials}

The next question refers to the frequency of printing electronic materials and the reasons why the students actually did it. Figure 3 presents the collected data. The results here are not univocal as paper-/screen-oriented subjects are also indicating the habit of printing the available electronic materials. The most numerous group constitute subjects who always print electronic materials, substantiating for their choices with the following arguments. 
Always: Always, because I prefer to write on my notes, Always. I learn better that way; Always. Because I can make notes; Always. Because I like to have paper version; Always. I hate reading on computer screen; Everyday; It is convenient to read and learn from paper sources; I prefer reading on paper, because it's more comfortable for me, I can add my own annotations on paper; I always print because it is need for classes; I always print what I have to read; Almost all the time because it is more comfortable for me to have things on paper; Always; Always because I hate reading on screen I do not do it if I do not have to; Very often because I don't like reading on screen; Very often I like have copies in hand; Always, because I want to make notes and I prefer reading on paper; Almost always because I have to have this on my lessons; Always it is the easy form to learn for me; I always print because it's more practical. For me; Almost always because I like physical contact with things; Always because I prefer to have paper version; Always when its obligatory; Almost all the time, it's easier; Almost always, it is easier for me to focus and I do necessary notes; I print everything I can; Always because I prefer reading form a paper; Because I prefer reading on the paper; Because I prefer reading on paper; Everyday; It happens daily I believe.

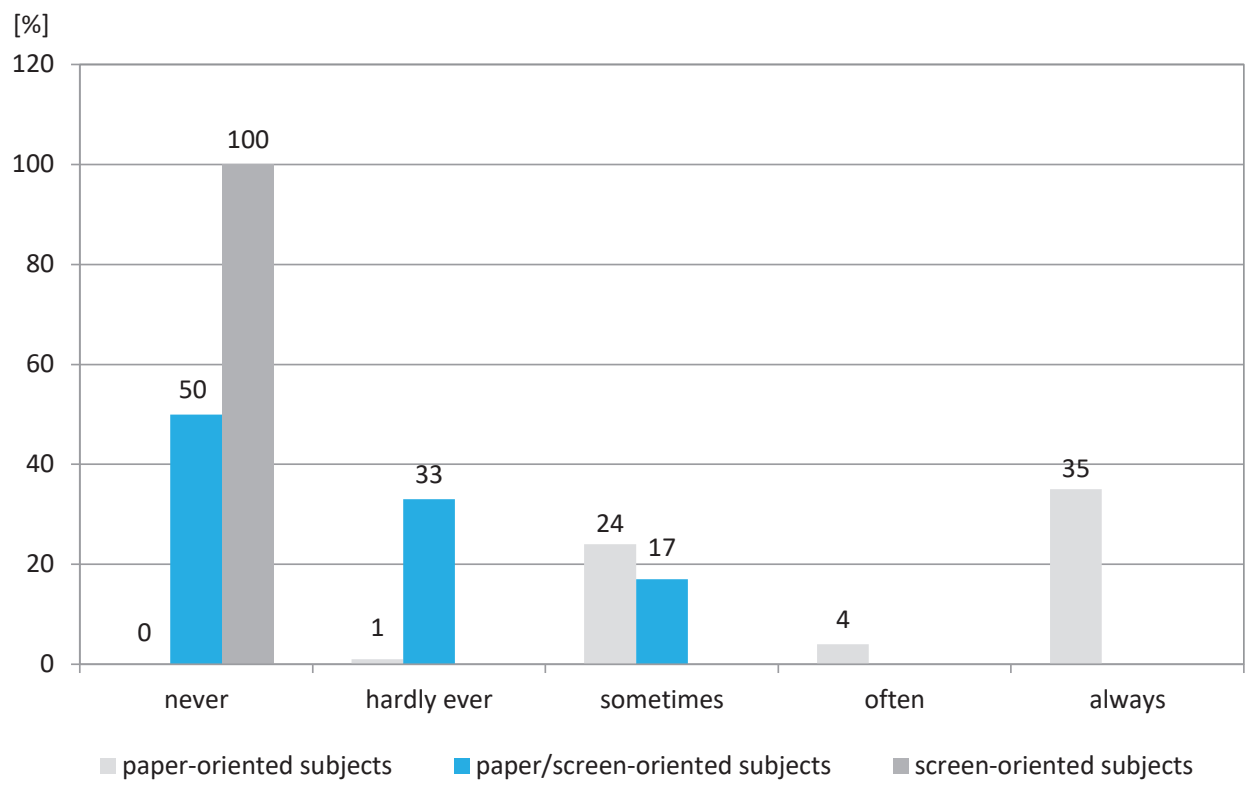

Figure 3. The frequency of printing electronic materials.

Often: Almost always, I prefer reading on paper, Almost always, because I can then make notes more freely; Quite often, because it's cheaper than buying books; Often, 70\% I prefer reading on paper; Almost always - I don't like 
reading in the screen; Often because it is easier and more practical; I usually do, because it helps me to focus on what I'm reading; Almost always, because I like to hold paper in my hand; I print it very often because it is obligatory to the uni; Very often because I prefer text on a paper; Very often because is more convenient; If it's short - often; In 70\% of the situation, when I had to take notes or when it's obligatory; Often to organize it better; Most of All; Very often. I want to have notes physically, because of no access to laptop and low memory in smartphone; Very often because it's easier for me to read from paper and more comfortable; Very often, for my class; Quite often, because I like collecting materials; As often as can. Because I prefer to read on paper; Pretty often, because it's easier for me to read on paper.

Sometimes: Only print material readed during classes; When I have to understand something profoundly; Because I like reading on the paper; Only if I have to mark some things; It depends; I print something when I need to read - always; Everytime I have classes; Few times in a week, because there are materials for school; I print what I have to read after classes at the university or before exams; Sometimes it depends on a subject; Usually I print things which are need to the university; Sometimes if it's obligatory for school; Sometimes, I print it when I want to note sth on the text; I like to have it with me if I want to read it; I have to bring it to Uni; Before exams \& when a teacher asks to do it; Only if I need it for classes because of notes I'd take.

Hardly ever: Not too often, I don't like wasting paper on stuff I can read on screen, I don't cause paper is expensive.

Never: I don't own a printer( $x 3)$, Never.

The action of printing the materials required for studying is the link connecting the two media, showing that students naturally find ways of developing interaction patterns between two media in question. From these results it is clear that the major reason for printing out the electronic texts is the same subjects provided in their preferred reading interface, it is a strong need for manipulating and alternating the original layout of the text.

\section{Self-perceived Ability to Remember the Information Read on Screen}

Another question refers to the ease of retrieval of the information presented electronically in which students are supposed to indicate why they think it is conducive to their retrieval of new information. The answers to the question are presented in Figure 4 in high, low or no difference category. It is important to highlight that none of the paper-oriented subjects indicated that information presented on the screen was conducive to the retrieval of new information.

Low: I can't focus at all, I can't stay focused; Not really, but if that would be the case, it would be only because I don't make notes on scree; Dunno, this 
is how I am, how God created me; I don't know; I can't focus while reading on screen; There are other distractions that way (Facebook etc.); Coz I can't make notes; I don't know why; When I try to read on screen, I can't remember anything; It doesn't matter if I read sth on screen or paper; I'm easily distracted while reading on screen; I don't like reading on screen, because it is disturbing me; Because I tired after half hour; Because things I read on screen stay in my mind for a short period of time; I don't like reading on screen; Because I don't like reading on screen; Sometimes I forget what I've been reading immediately after I've read it, No. Because I can't focus on the information but on FB messages, I need writing those information; My eyes are tired; I couldn't concentrate on the text, which I read on screen; Because of having only files is smartphone which has small screen; I don't know why; I do not use e-books; The paper is more physical for me; I don't like reading things on screen; Because a lot of thing burn me; I cannot focus on screen because I always distract myself by doing some other things; I don't know, maybe because I prefer paper; Because reading on screen makes me tired quickly; Because I can't remember where I learned about sth; Because I'm distracted; It's too bright and the font's too small; I can't make notes and focus properly; I can't easily focused when I have to read something on the screen; I think this method of learning is distracting; I feel tired when I spent my time in front of

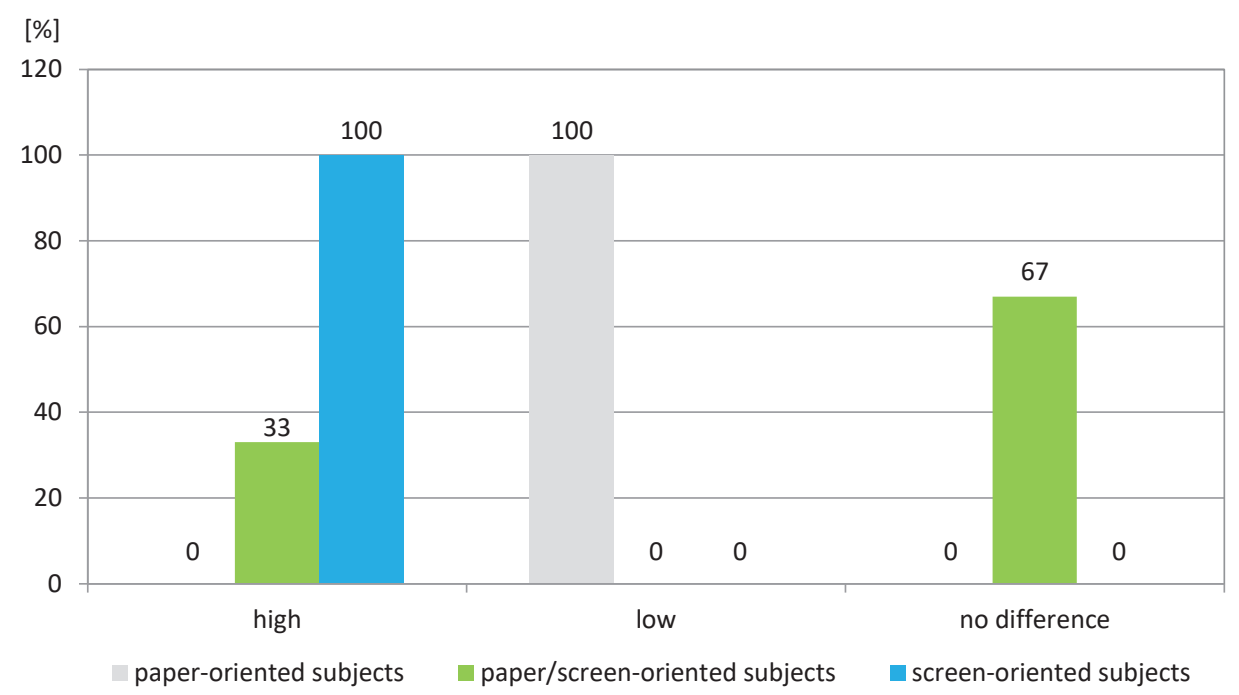

Figure 4. Self-perceived ability to remember the information read on screen.

High: I don't know; Yes. Because I'm totally the cyber type of person who really remember info from the screen... 
No difference: It doesn't matter which material I read; No. I think it's the same or worse; I don't think there is a difference; I think it is a matter of feeling comfortable); No opinion; No, It's same for me; No difference.

The paper-oriented readers seem to be more strategic as they intentionally avoid distractions and attempt to provide for themselves an environment that would be most conductive for learning. They are also more aware and observant as far as their memory functioning is concerned.

\section{Critical Thinking Skills}

The last set of questions regards critical skills involving understanding complex ideas, evaluating evidence, weighing alternative perspectives and constructing justifiable arguments. Subjects' preferred interface for understanding complex ideas is illustrated in Figure 5. As the results show, the majority of subjects choose paper for comprehension of complex ideas, which indicates their intuitive understanding of how to use note taking, graph drawing, and highlighting possibilities, which are offered by manipulation of paper, to their best advantage.

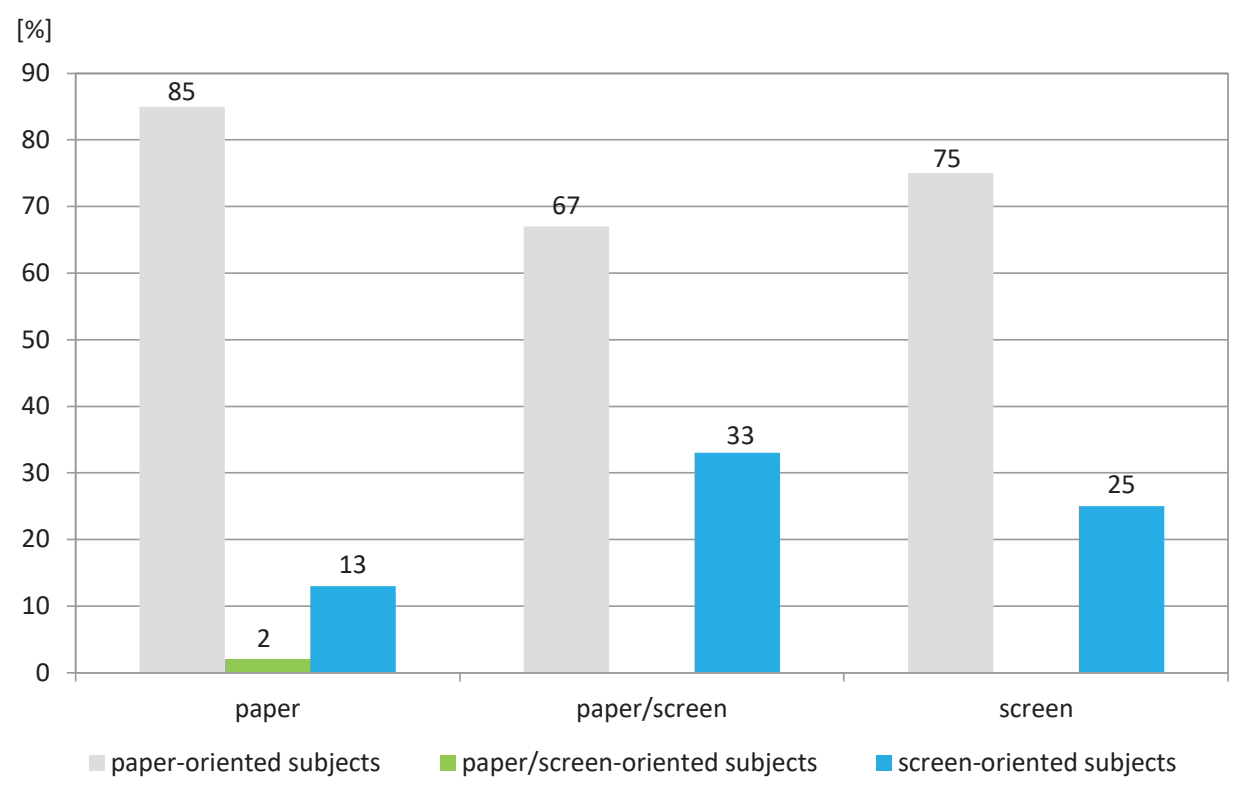

Figure 5. Interface chosen for understanding complex ideas.

As far as interface preferred for evaluating evidence, the results, which are quite surprising, are shown in Figure 6. 


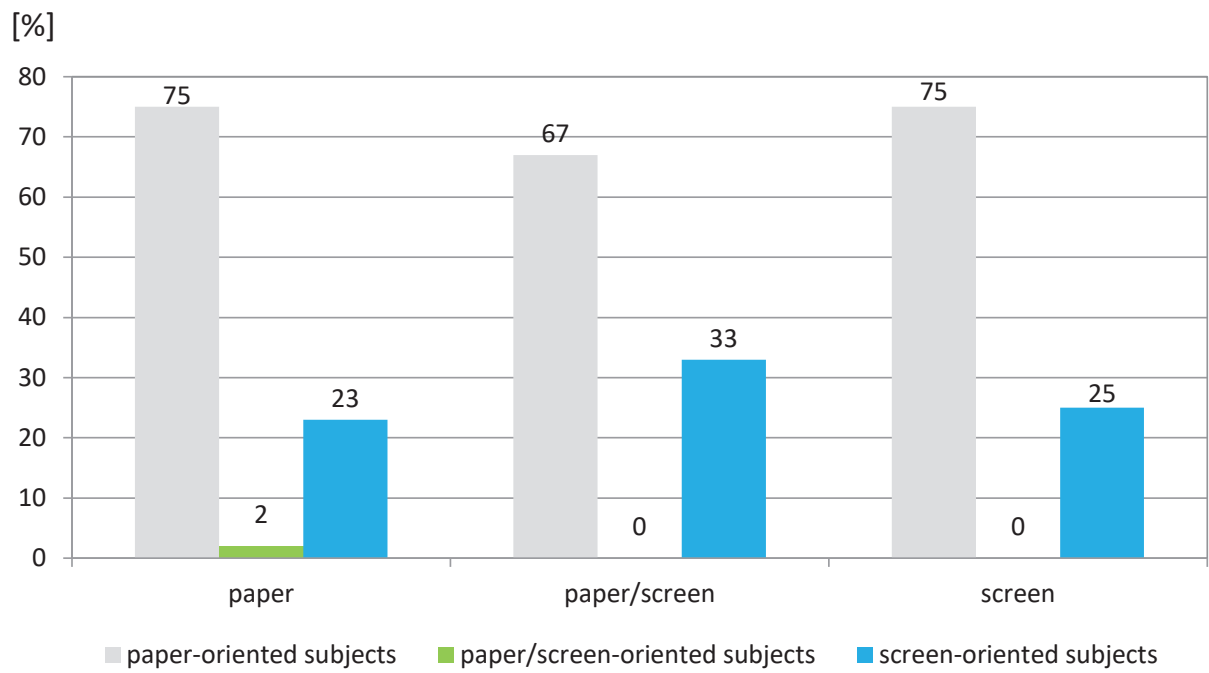

Figure 6. Interface chosen for evaluating evidence.

The slight decrease in paper preference by subjects who are paper-oriented can be observed in the results, the surprising answers are yielded by both paper/ screen and screen-oriented subjects, as their choices do not involve paper/screen option. This is the element that might be due to their lack of expertise in doing research and this is the element that will hopefully be developed when writing their BA and MA projects.

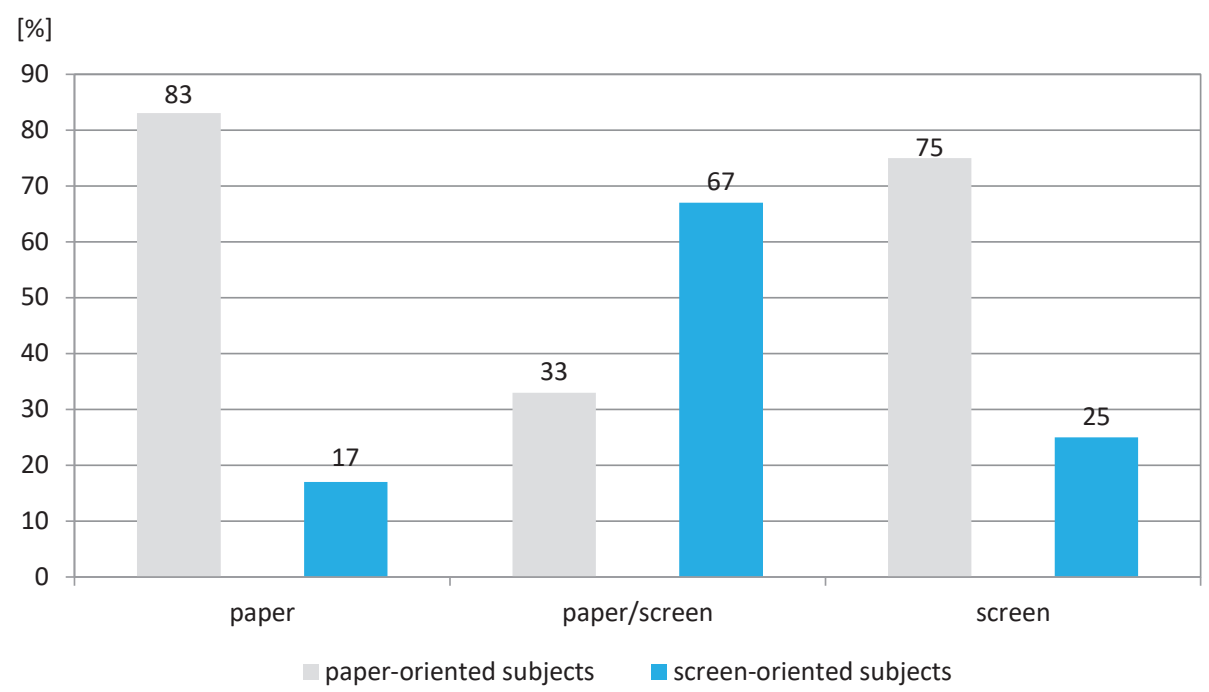

Figure 7. Interface chosen for distinguishing between facts and opinions as well as constructing justifiable arguments. 
As regards assessing subjects' preferences as far as distinguishing between facts and opinions and constructing justifiable arguments are concerned, the interface chosen is either paper or screen without the option of both. That is why only the two of them are presented in Figure 7.

The results in this area are polarised in that subjects either choose paper or screen, which indicates the fact that switching between links may appear difficult and attention draining. In this particular question it appears to be surprising as it can be assumed that distinguishing between facts and opinion would automatically involve the shift between available media. On the whole, it can imply the flaw of the question asked, which for further study should be divided into two questions, namely, distinguishing between facts and opinion as a separate question, and another one for constructing justifiable arguments. It is the construction of justifiable arguments that could have biased the answer to the question as paper is associated by subjects with greater reliability. It would be interesting to investigate how students' critical thinking skills develop during the course of their tertiary education training and how their views on application of both interfaces change.

\section{Conclusions and Further Study Suggestions}

From the results presented above, several conclusions can be drawn. The first one does not support our initial assumption concerning the increase in paper/screen orientation of the readers caused by the rapid development of technology. On the contrary, since Ramirez Leyva's (2006) study there is a 7\% increase in paper preference in ours. Despite the fact that our study suffers from the limitation connected with a considerably small number of subjects, we might speculate that such increase in paper preference might be due to the olfactory determinant that readers are not aware of, but subconsciously strongly attached to. There is only one subject who reported to like the smell of pages and it has not been mentioned in previous studies but deserves to be further investigated. It would also be interesting to view students preferences longitudinally and examine if they change during the course of their studies. Writing BA and MA projects constitutes a powerful tool for teaching thinking skills and students will certainly benefit from accessing and utilising electronic tools available for doing research.

The next conclusion that can be drawn from our study is that the instant access to any material one wishes surprisingly neither contributes to a rocketing foreign language learning results nor contributes to the development of critical thinking. On the above basis, it can also be concluded that teachers cannot take 
for granted that students know how to function in knowledge society. That is why teachers should be aware of students' preferred reading interface and their teaching techniques have to be based on real science, not rumour or mythology. The mere indication of the differences between e-reading and paper reading can constitute a powerful awareness raising tool. As the results show, subjects seem to have the intuitive understanding of how best to find, comprehend, and retain the text, as they start looking for data on-line and then print them out for in-depth studying, this intuitive understanding has to be reinforced by an overt digital literacy training.

In addition, our findings provide insight into students' overconfidence regarding what they really understand when they read from digital interface. As the results show, it is the screen-oriented group who makes greatest number of mistakes, especially in cases of language irregularities (that first have to be noticed to be stored), for example informations (original spelling). Teaching them to be mindful in their digital reading (for instance, by writing down key words from the text and sharing them with their mates in social media) may facilitate learning, which is yet another skill that has to be overtly trained and developed.

Our results on the interface preference as far as the facility of remembering information are broadly consistent with the results regarding students' preferred reading interface, again indicating strong paper orientation. What is also apparent from the results obtained is the fact that digital reading is not the sort of reading likely to nurture the critical thinking. That is why developing digital literacy skills should go hand in hand with the development of critical thinking skills. The data collected in the study clearly indicate that both paper and screen-oriented students do not use the full potential offered by reading texts in an electronic version, as for most of the critical thinking skills they chose paper interface. However, as far as basing judgement on evidence is concerned, digital texts read from the screen, no matter how distracting they may be, provide hyperlinks, which if used strategically and in a disciplined way are an indispensable tool for collecting data. With reference to the component of evaluating evidence, it is possible to assume that asking penetrating questions, which is instantaneously at students' fingertip when using search engines, will be facilitated by a simple print out of core ideas/materials. Future studies could fruitfully explore the issues of weighing alternative perspectives and constructing justifiable arguments with reference to the fact that electronic text approaches new issues, offering visual clues allowing the reader to switch between hypertext and videos. The fact is that students need to be trained in both paper and digital literacy skills, to complement and use the potential available in both interfaces. The academic performance of paper, paper/screen, and screen-oriented groups of subjects constitutes an interesting further research suggestion so as to check which of the groups uses their preferences to their 
best advantage. Further studies should investigate the issue of improving students digital literacy by means of developing basic computer skills in the area of electronic annotation mechanism.

Looking forward, further research concerning changes the reading skill undergoes will provide a sound base for the development of the congruent pattern of interaction between paper and screen interface, as they both have a great influence on critical thinking skills of the readers. Further studies should also investigate how the new technologies follow the results of the studies on reading from both paper and screen interface, at the same time focusing on well-developed paper literacy as a point of departure.

\section{References}

Bennett, S., Maton, K., \& Kervin, L. (2008). The 'digital natives' debate: A critical review of the evidence. British Journal of Educational Technology, 39(5), 775-786.

Bennett, B., \& Rolheiser, C. (2001). Beyond Monet: The artful science of instructional integration. Toronto: Bookation, Inc.

Broek, P. (2018). Comprehension processes in digital reading. Learning to read in a digital world. Amsterdam: John Benjamins.

Dillon, A. (1992). Reading from paper versus screens: A critical review of the empirical literature. Ergonomics, 35(10), 1297-1326.

Durant, D. M., \& Horava, T. (2015). The future of reading and academic libraries. Libraries and the Academy, 15, 5-27.

Gibbons, A. (2017). Archaeology. Human Evolution. doi:10.1126/science.aan6934

Gudinavičius, A. (2016). Towards understanding the differences between reading on paper and screen: Measuring attention changes in brain activity. Libellarium: časopis za povijest pisane riječi, knjige $i$ baštinskih ustanova, 9(1), 175-184.

Hanho, Jeong. (2012). A comparison of the influence of electronic books and paper books on reading comprehension, eye fatigue, and perception. The Electronic Library, 30(3), 390-408, doi: 10.1108/02640471211241663

Jabr, F. (2018). The reading brain in the digital age: The science of paper versus screens. Scientific American. Retrieved from: www.scientificamerican.com/article/reading-paperscreens/

Josselson, R. (1994). Identity and relatedness in the life cycle. In H. A. Bosma, T. L. G. Graafsma, H. D. Grotevant, \& D. J. de Levita (Eds.), Identity and development: An interdisciplinary approach (pp. 81-102). Thousand Oaks, CA: Sage.

Kaufman, G., F., \& Flanagan, M. (2016). High-ow Ssplit: Divergent cognitive construal levels triggered by digital and non-digital platforms. In Proceedings of the $2016 \mathrm{CHI}$ Conference on Human Factors in Computing Systems, 2773-2777.

Kol, S., \& Schcolnik, M. (2000). Enhancing screen reading strategies. CALICO Journal, 18, $67-80$.

Kress, G. (1985). Linguistic Processes in Sociocultural Practice. Oxford: Oxford University Press. 
Mangen, A., Walgermo, B. R., \& Brønnick, K. (2013). Reading linear texts on paper versus computer screen: Effects on reading comprehension. International Journal of Educational Research, 58, 61-68.

Murphy Paul, A. (2013). How reading can be like falling in love. Deep, immersive reading offers far more benefits than just pleasure. Retrieved from: The Brilliant Blog. https://www. nextavenue.org/how-reading-can-be-falling-love/

Nicholas, A. J., \& Lewis, J. K. (2008). Millennial attitudes toward books and e-books. The International Journal of the Book, 5(2), 81-92.

Ramírez Leyva, E. M. (2003). The impact of the internet on the reading and information practices of a university student community: The case of UNAM, NewReview, of Libraries and Lifelong Learning, 4(1), 137-157.

Roser, M., \& Ortiz-Ospina, E. (2018). Global Rise of Education. Retrieved from: https://our worldindata.org/global-rise-of-education

Salmerón, L., Cerdán, R., \& Naumann, J. (2015). How adolescents navigate Wikipedia to answer questions? Infancia y Aprendizaje, 38, 435-471.

Salter, P. (2018). Impact of reading from a screen versus from printed material. Retrieved from: http://www.radford.act.edu.au/storage/reading-on-screens-v-paper.pdf

Schumm, S., \& Post, J. S. (1997). Executive learning: Successful strategies for college reading and studying. Upper Saddle River, NJ: Prentice Hall.

Sellen, A. J., \& Harper, R. H. R. (2001). The myth of the paperless office. London: MIT Press.

Vidal-Abarca, E., Mañá, A., \& Gil, L. (2010). Individual differences for self-regulating taskoriented reading activities. Journal of Educational Psychology, 102, 817-826.

Walsh, G. (2016). Screen and paper reading research-A literature review. Australian Academic and Research Libraries, 47(3), 160-173.

Wästlund, E., Norlander, T., \& Archer, T. (2008). The effect of page layout on mental workload: A dual-task experiment. Computers in Human Behavior, 24(3), 1229-1245.

Wolf, M. (2007). Proust and the squid: The story and science of the reading brain. New York: HarperCollins.

Wolf, M. (2010). Our 'deep reading' brain: Its digital evolution poses questions. Retrieved from: http://niemanreports.org/articles/our-deep-reading-brain-its-digital-evolution-poses -questions/

Wu, M-D., \& Chen, S-C. (2011). Graduate students' usage of and attitudes towards e-books: Experiences from Taiwan. Program: Electronic Library and Information Systems, 45(3), 294-307.

Zambarbieri, D, \& Carniglia E (2012). Eve movement analysis of reading from computer displays, eReaders and printed books. Ophthalmic Physiol Opt. 32(5), 390-396.

Agnieszka Ślęzak-Świat

\section{Zur Entwicklung der Lesefertigkeit im 21. Jahrhundert: Komplementarität der Papier- und Elektroschnittstelle}

\section{Zusammenfassung}

Die Lesefertigkeit unterliegt eindeutigen Veränderungen, weil die Lesenden den Zugang zu Texten nicht nur in gedruckter, sondern auch in elektronischer Form haben. Eine der Fragen, die in diesem Beitrag erörtert werden, betrifft die Präferenzen der Lesenden in Bezug auf die (Papier- oder Elektro-)Plattform, aus der sie den Text lesen. 
Die durchgeführte Studie zielt darauf ab, homo legens, insbesondere Studierende der Englischen Philologie aus dem ersten Jahr, hinsichtlich ihrer Präferenzen, Lernweise und ihrer kritischen Einstellung zu einem sowohl in gedruckter als auch in elektronischer Form verfügbaren Text zu bewerten. Die Analyse der gesammelten Daten ermöglicht es eindeutig, auf den Text in gedruckter Form zu verweisen, die durch die überwiegende Mehrheit der Befragten (87\%) als eine bevorzugte Plattform für die Übermittlung eines Textes bezeichnet wird, was auch die Ergebnisse der zuvor durchgeführten Untersuchungen bestätigt.

Die Beobachtung der Veränderungen in der Dynamik der Präferenzen von Texten, die in gedruckter und elektronischer Form zugänglich sind, trägt zur Schaffung eines optimalen Interaktionsmusters dazwischen bei, wodurch auch die Fähigkeit zum kritischen Denken verbessert wird.

Die künftigen Forschungen sollten sich darauf konzentrieren, wie digital literacy unter Verwendung der Papierschnittstelle als Ausgangspunkt erfolgreich entwickelt werden kann.

Schlüsselwörter: literacy, Lesen vom Bildschirm vs. Lesen von Papier, Notizen machen, kritisches Denken, digital literacy 
